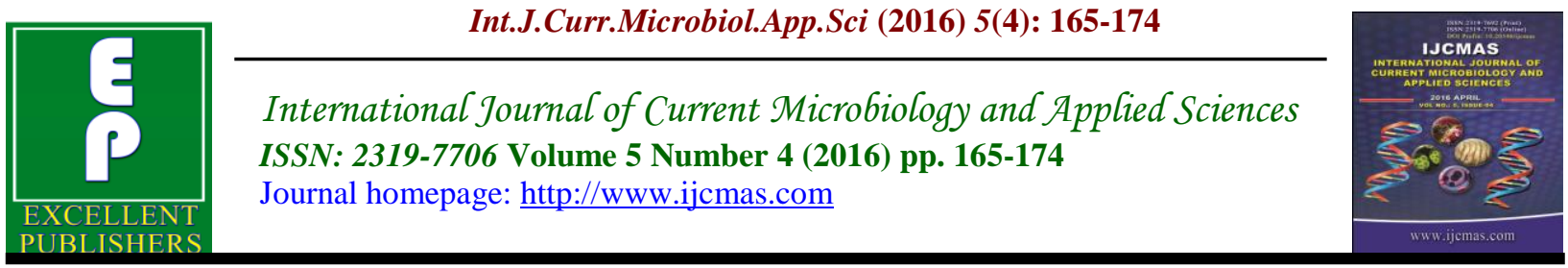

Original Research Article

http://dx.doi.org/10.20546/ijcmas.2016.504.021

\title{
Effect of Mycorrhizal Association on Nodule Number, Mass, Leghaemoglobin and Free Proline Content in Macrotyloma uniflorum (Lam.) Verdc. Under PEG Induced Water Stress
}

\author{
Savitha M. Murthy ${ }^{1}$, P. Anitha ${ }^{2}$, B.S.Sumalatha ${ }^{3}$ and D.H. Tejavathi ${ }^{3 *}$ \\ ${ }^{1}$ Department of Botany, Mount Carmel College, Bangalore - 560 023, India \\ ${ }^{2}$ Department of Botany, MES College, Bangalore - 560 003, India \\ ${ }^{3}$ Department of Botany, Bangalore University, Bangalore - 560 056, India \\ *Corresponding author
}

\section{A B S T R A C T}

Keywords

Legumes,

AM fungi,

Nodulation,

Leghaemoglobin,

Proline,

Macrotyloma

uniflorum.

\section{Article Info}

Accepted:

15 March 2016

Available Online:

10 April 2016
Seeds of Macrotyloma uniflorum were fed with various concentrations of PEG ranging from 5 to $25 \%$ during germination and continued till 45 days after germination on alternate days to induce water stress. Inoculums of Glomus mosseae and $G$. fasciculalum were added to the soil in pot experiment before sowing the seeds. Nodule number, mass, leghaemoglobin and proline contents were estimated in 45 days old plants of unstressed, induced stressed, unstressed AMF treated and stressed AM fungal treated. Observations revealed that AM fungal association improves the number and mass of nodules along with enhanced contents of leghaemoglobin under induced stressed condition. Content of proline in leaves is increased under induced stress in both mycorrhizal and non mycorrhizal plants. However the increase is more evident in non mycorrhizal plants than AM fungal treated plants under induced stress indicating better osmotic adjustment by AM symbiosis. Among the two AM fungal species, G. mosseae is more compatible with the host by improving all the parameters studied than $G$. fasciculalum inoculated plants indicating its host specificity. The significance of AM fungal association in the process of nodulation of legumes is discussed.

\section{Introduction}

Arbuscular mycorrhiza forms a symbiotic association with roots of $90 \%$ of the species belonging to angiosperms, gymnosperms, pteridophytes and bryophytes (Mishra et al., 1980; Williams et al., 1994). AM fungal symbiosis improves the growth performance of host through the ability of extra radical fungal hyphae to take up nutrients, particularly phosphorus from soil (Verma and Hock, 1998). High requirement of phosphorus is essential for nodulation and nitrogen fixation process by bacteria in legumes (Barea and Azcon-Aguilar, 1983). Nitrogen fixation in nodules is severely affected by various environmental hazards mainly draught and salinity. When legumes are exposed to these adverse conditions, both nodulation and process of nitrogen fixation are affected. The notable effect of drought on nodulation is the premature 
nodule senescence and thereby decreasing the ability for nitrogen fixation. RuizLozano et al. (2001) have shown that drought induced nodule senescence in legume plants could be ameliorated by AM fungal association. It is now well established in various plant systems that AMF association can protect the host from adverse effects of drought (Allen and Allen 1986; Ruiz-Lozano et al., 1995; Goicoechea et al., 2005; Hazzoumi et al., 2015). Macrotyloma uniflorum, commonly known as horse gram, is highly nutritious and cultivated for the seeds. It is an excellent source of molybdenum. It is mainly grown in arid and semiarid regions because of its drought tolerance to some extent. Though the taxon is extensively studied for its nutritional value and biochemical studies, it is still an under exploited crop with respect to sustainable agricultural practices (Sudha et al., 1995; Reddy et al., 2005; Siddhuraju and Manian, 2007; Bhartiya et al., 2015). Hence, the present study is to evaluate the effects of AM fungal association on the nodulation, biosynthesis of leg haemoglobin and proline in unstressed, induced stressed, unstressed AM fungi treated and induced stressed AM fungi treated plants.

\section{Materials and Methods}

Seeds of Macrotyloma uniflorum (Lam.) Verdc. var. PHG-9 were procured from University of Agricultural Sciences, Bangalore. Seeds were soaked in sterile distilled water for $24 \mathrm{~h}$ before planting them in pots containing sterile soil. Pots used for the experiment are uniformly sized pots (7x7) of capacity of holding $4 \mathrm{Kg}$ of sterilized soil (autoclaved twice at $108 \mathrm{kpa}$ for $15 \mathrm{~min}$.). In one set of experiment, presoaked seeds sown in the pots containing sterilized soil were watered on alternate days for 45 days. In second set of experiment, pre-soaked seeds sown in the pots containing sterilized soil were fed with various concentrations of PEG (mol.wt.6000) ranging from 5-25\% on alternate days for 45 days. For the third set of experiment, the inoculums of Glomus mosseae and G. fasciculatum were obtained from the department of Microbiology, University of Agricultural Sciences, Bangalore which consist of sand and soil mixture with spores, extraradical mycelia and mycorrhizal root segments of Rhodes grass. $0.8 \mathrm{~g}$ of inoculum of both the species (1 gm: 1 lakh propagules) was placed at the depth of 2-3 cms from the soil surface. Presoaked seeds for $24 \mathrm{~h}$ were pushed down to $1.5 \mathrm{cms}$ deep in the soil and covered by the surrounding soil and watered for alternate days which continued up to 45 days. For fourth set of experiment, pre-soaked seeds sown in pots containing AMF inoculums were fed with various concentrations of PEG ranging from $5 \%$ to $25 \%$ on alternate days for 45 days. The seeds were germinated within one or two days. 45 days old plants were selected for nodulation studies, estimation of leghaemoglobin and proline content. Experiment was designed in randomized block design with 12 replicates of each treatment (one plant per pot).

The following set of experiments were conducted

\section{Seeds fed with water- control-S}

2. Seeds fed with PEG at various concentrations $(5-25 \%)$

3. Seeds treated with G.mosseae-controlGM

4. Seeds treated with G.mosseae and PEG $(5-25 \%)$

5. Seeds treated with G. fasciculatumcontrol-GF 
6. Seeds treated with G.fasciculatum and PEG $(5-25 \%)$

\section{Nodulation Studies}

Randomly five healthy plants were carefully uprooted and thoroughly washed under running water. Nodules per plant were counted and excised and weighed to note the weight of the nodules. Average weight of nodules from five plants was expressed in grams and recorded.

\section{Estimation of Leghaemoglobin (Lb)}

Leghaemoglobin content in the nodules was estimated following La Rue and Child method (1979). $100 \mathrm{mg}$ of root nodules were weighed and homogenized in $10 \mathrm{ml}$ of pyridine. Pyridine was added drop by drop along with a pinch of sodium dithionate during homogenation. The homogenate was centrifuged at $3000 \mathrm{rpm}$ for 10 minutes. Supernatant was collected and made up to $10 \mathrm{ml}$ using pyridine. Absorbance was taken at $540 \mathrm{~nm}$ and pyridine served as blank. Lb content was calculated against a standard graph drawn for hemin at $10 \mu \mathrm{g} / \mathrm{ml}$.E

\section{Estimation of Proline}

Proline content in the leaves was estimated according to Bates et al., method (1973). $100 \mathrm{mg}$ of the leaf sample were weighed and homogenized into a fine paste in $10 \mathrm{ml}$ of $35 \%$ sulphosalicylic acid. The homogenate was centrifuged for 5-10 min. $2 \mathrm{ml}$ of supernatant was taken and to that $2 \mathrm{ml}$ of glacial acetic acid and $2 \mathrm{ml}$ of acid ninhydrin were added. The sample was heated on a water bath for $1 \mathrm{~h}$ and the reaction was terminated by keeping in the ice cold conditions. $4 \mathrm{ml}$ of toluene was added and the absorbance was read at $520 \mathrm{~nm}$. Free proline was calculated against the standard graph for proline.

\section{Data Analysis}

Twelve replicates per treatment were established (one plant per pot). The data thus obtained from the experiment was subjected to one way analysis of variance (ANOVA) for completely randomized design. Significant $\mathrm{F}$ ratios between the group means were further subjected to DMRT using SPSS version 1.5. Probability values $<0.05$ were considered as significant (Snedecor and Cochron 1994)

\section{Results and Discussion}

\section{Nodule Number}

Gradual increase in the number of nodules has been observed in AM fungal treated plants under both with and without induced stress by various concentrations of PEG (Fig.1). Whereas in non mycorrhizal plants there is a gradual decrease in the number of nodules as the concentration of PEG increases under stress condition. Maximum number of nodules, $88.00 \pm 0.87$, was developed in the plants treated with $G$. mosseae at the concentration of $25 \%$ of PEG treatment and minimum of $61.00 \pm 0.33$ was recorded under 5\% Of PEG treatment. The number of nodules recorded at $25 \%$ of PEG treatment in stressed plants without AM fungal association is being $12.00 \pm 0.23$ as against $88.00 \pm 0.87$ in G. mosseae treated and $82 \pm 0.66$ in $G$. fasciculatum treated plants under induced stress. In control plants the number of nodules is recorded as $50.00 \pm 0.32$ in Control-S, $55.00 \pm 0.58$ in control-GM and $52.00 \pm 0.25$ in control-GF plants.

\section{Nodule Mass}

The nodule mass has shown a gradual increase as the concentration of PEG increases from $5 \%$ to $25 \%$ in AM fungal 
associated plants under both with or without induced stress (Fig.2). Correspondingly decrease in the nodule mass was observed in non mycorrhizal plants under gradual induced stress. The mass of the nodule in stressed plants without AM fungal association is recorded as $11.60 \pm 0.34$ at $25 \%$ of PEG treatment as against $52.00 \pm$ 0.66 in induced stressed G. mosseae and $50.20 \pm 0.34$ in $G$. fasciculatum treated plants. The nodule mass in control plants is being $30.00 \pm 0.55$ in control-S, 38.50 \pm 0.67 in $G$. mosseae treated and $36.00 \pm 0.78$ in G.fasciculatum treated plants.

\section{Leghaemoglobin Content (Lb)}

The content of $\mathrm{Lb}$ in nodules has gradually decreased in non mycorrhizal plants as the concentration of PEG increases (Fig.3). However, in mycorrhizal plants, gradual increase in $\mathrm{Lb}$ was recorded under induced stress. The maximum amount of leghaemoglobin, 21.22. $\pm 0.25 \mathrm{mg} / \mathrm{g}$ was found in G. mosseae treated plants at $25 \%$ of PEG treatment as against $2.51 \pm 0.18 \mathrm{mg} / \mathrm{g}$ in non mycorrhizal at the same concentration of PEG treatment. Whereas in G. fasciculatum treated plants the leghaemoglobin content was found to be $19.30 \pm 0.98$ at $25 \%$ PEG treatment. Leghaemoglobin content in control plants are recorded as $9.77 \pm 0.18$ in control-s plants, $10.01 \pm 0.45$ in control-GM and $10.21 \pm 0.23$ in control-GF plants.

\section{Proline Content}

Increase in proline content was observed in both nonmycorrhizal and mycorrhizal plants as the concentration of PEG increases (Fig.4). Proline content was found to be $140.90 \pm 0.67 \mu$ moles/g at the concentraction of $25 \%$ of PEG in G. mosseae treated plants, whereas $138.80 \pm 0.66 \mu$ moles/g was recorded in G. fasciculatium treated plants.
However in induced stressed plants without AM fungal association, the content is slightly more $(145.20 \pm 0.66)$ at $25 \%$ of PEG treatment. Proline content in control plants are being $70.78 \pm 0.67$ in control-S, $73.21 \pm 0.83$ in $G$. mosseae treated and $69.24 \pm 0.67 \mu$ moles $/ g$ in G.fasciculatum treated plants.

Majority of legumes form symbiotic association with both phosphorus acquiring AM fungus and nitrogen fixing bacteria in tripartite relationship. Mycorrhizal fungi are known to have some beneficial effect on the growth of the host though various ways (Gianinazzi and Gianinazzi-Pearson 1988). The symbiotic association improves the efficiency of the host to uptake nutrients particularly phosphorus and water from the rhizospheric soil by enhancing the absorption surface (Varma and Hock 1998). Nitrogen fixation by legumes is greatly sensitive to drought stress particularly in tropical taxa. Under drought conditions symbiotic nitrogen fixation is one of the physiological processes to shown first stress responses in nodulated legumes. One of the detrimental effects that will be shown during drought will be the premature nodule senescence and thereby decreasing the ability for nitrogen fixation (Ruiz-Lozano et al., 2001). Premature nodule senescence triggered by stress causes an acceleration of lytic activities and formation of green pigments (Sarath et al., 1986).In the present studies, the number of nodules and their mass were increased in AM fungal treated plants under unstressed and stressed by various concentrations of PEG. A slight increase in the number of nodules produced in $G$. mosseae treated plants compared to $G$. fasciculatum treated plants. Decline in the number of nodules and their mass have been observed under induced stress by PEG treatments in non mycorrhizal plants. The number of nodules recorded at $25 \%$ of PEG 
treatment in stressed plants is being $12.00 \pm$ 0.23 as against $88.00 \pm 0.87$ in $G$. mosseae treated plants. Correspondingly, the mass of the nodule in stressed plants is recorded as $11.60 \pm 0.34$ at $25 \%$ of PEG treatment as against $52.00 \pm 0.66$ in induced stressed $G$. mosseae treated plants. Even in the control plants, AM fungal treatments have enhanced the number and mass of the nodules. Tajini et al. (2012) have reported significant increase in nodular mass and number in AMF treated plants of Phaseolus vulgaris. AMF inoculation increases the nodule number, mass and overcome the salinity stress in Sesbania sesban (Abd-Allah et $a l ., 2015)$. Water deficit conditions according to Lobota et al., (2009) decrease the root capacity and liberate the exudates responsible for nodulation, thereby reducing the nodule number. Whereas in AMF treated plants water deficit condition can be ameliorated. Nodule number and mass was declined drastically under severe drought conditions in Lupinus varins (Younis, 2002). However, Jia et al. (2004) have found no significant difference in nodular mass between AMF treated plants and control plants of Vicia faba. The involvement of AM fungi with drought tolerance is considered to be related to phosphorus nutrition and is therefore of particular interest to nitrogen fixation in legumes in view of direct or indirect impact of phosphorus on nodule formation and function (Bethlenfalvay et al., 1987).
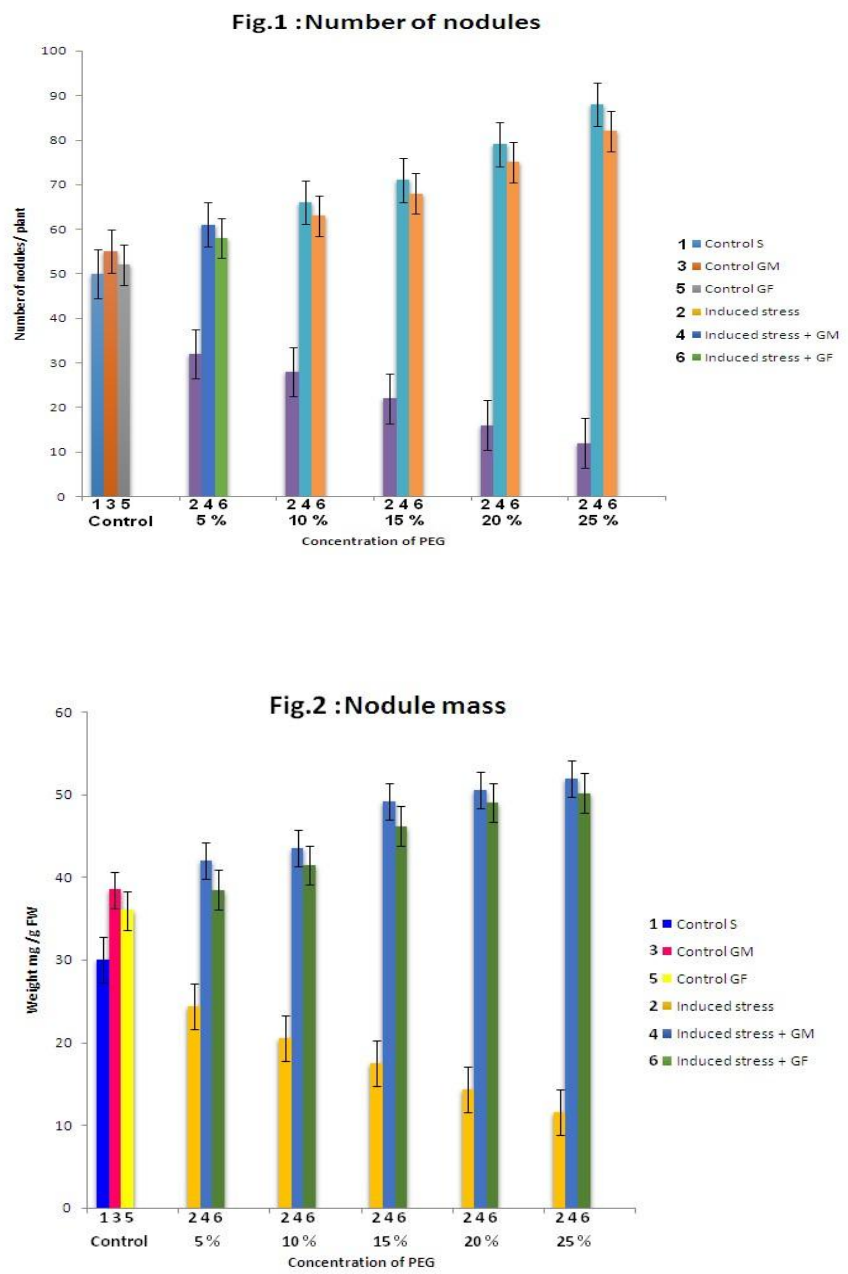
Fig.3: Leghaemoglobin

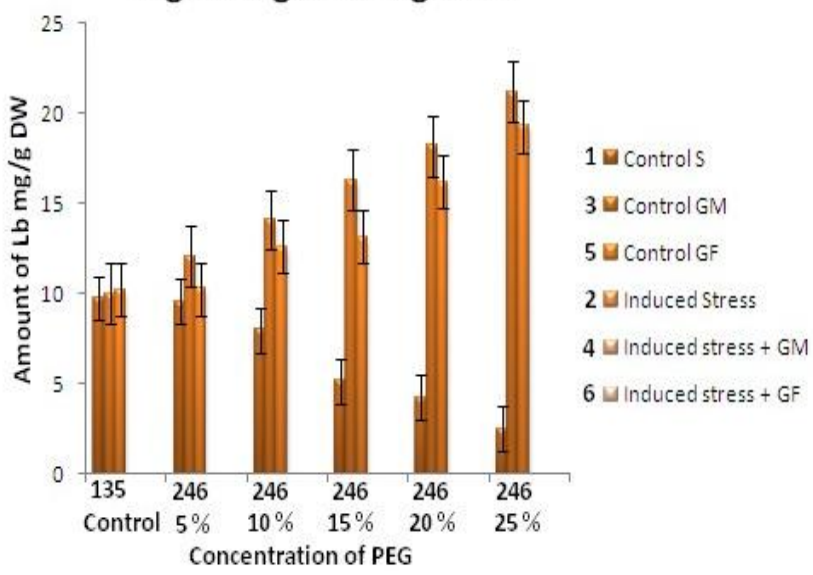

Fig.4 :Free Proline

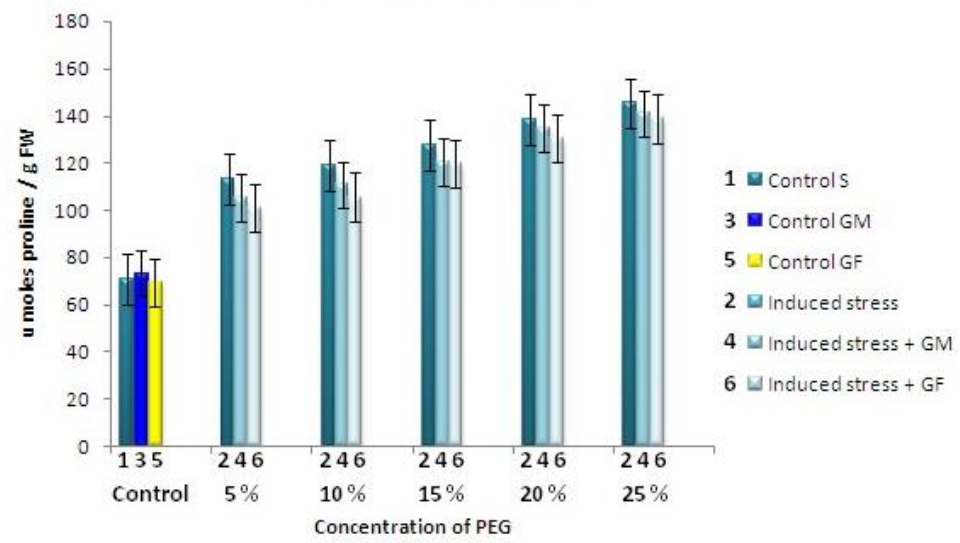

Leghaemoglobin, an oxygen binding hemoprotein, controls the activity of nitrogenease, an enzyme responsible for the fixation of atmospheric nitrogen by buffering the concentration of free oxygen in the cytoplasm of bacterial infected cells. Steady increase in the concentration of leg haemoglobin was recorded in the AM fungal treated plants under induced stress by the application of various concentration of PEG. However, there is decrease in the content of leghaemoglobin in the non mycorrhizal stressed plants. As the concentration of PEG increases, the total amount of leg haemoglobin in G. mosseae treated induced stressed plants was found to be $21.22 . \pm 0.25$ $\mathrm{mg} / \mathrm{g}$ at $25 \%$ of PEG treatment as against
$2.51 \pm 0.18$ in non mycorrhizal induced stressed plants at the same concentration of PEG treatment. G. mosseae colonized soyabean plants have shown high content of leghaemoglobinin both in watered and drought stress condition than other AM fungal treatments (Ruiz-Lozano et al., 2001). Gradual decline in the content of Lb in the nodules during drought conditions has been reported in several taxa (Abd-Alla and Wahad 1995; Ramos et al., 1999; RuizLozano et al., 2001; Younis 2002; Loboto et al., 2009). Changes in the contents of Lb have been suggested as the main effect on nodule metabolism caused by drought (Irigoyen et al., 1992) which results in decline in nitrogen fixation that limit oxygen 
supply to bacteroids and affect respiration and energy production (Gonzalez et al., 1998). The importance of AM symbiosis in legume plants has been traditionally attributed to the high $\mathrm{P}$ requirement of nodulation and $\mathrm{N}_{2}$ fixation process (Barea and Azcon-Aquilar, 1983; Ruiz-Luzano et al., 2001). AM fungal associated plants are better equipped for more $\mathrm{P}$ absorption than non AM fungal associated plants.

Water stressed plants are known to accumulate organic osmolytes such as proline and sugars that contribute to the host plant tolerance under drought through enhanced osmoregulation (Trotel-Aziz et al., 2000). In the present study proline levels were increased in both induced stressed non mycorrhizal and mycorrhiza treated plants. However, the contents in the non mycorrhizal induced stress plants were slightly more compared to mycorrhizal plants. Proline accumulation correlates with drought resistance in various plant species (Parcel et al., 2003; Farahani et al., 2008; Bhosale and Shide 2011; Hazzoumi et al., 2015). Proline content in roots colonized by AM fungi is significantly less as compared to non AM fungi indicating osmotic adjustment thereby enhancing the ability of the host to cope up with the water stress (Porcel et al., 2003; Kohler et al., 2008). Proline content was found to be $140.90 \pm 0.67$ $\mu$ moles/g at the concentraction of $25 \%$ of PEG in G. mosseae treated plants whereas $138.80 \pm 0.66 \mu$ moles/g was recorded in $\mathrm{G}$. fasciculatium treated plants. However in induced stressed plants without AM fungal association, the content is slightly more (145.20 \pm 0.66$)$ at $25 \%$ of PEG treatment. Mycorrhizal plants exhibit the lowest nodule proline accumulation as a consequence of drought is an indication of less dehydration than nonmycorrhizal plants (Ruiz-Lozano 2001). Increase in proline content in non mycorrhizal plants of Zingiber ( Bhosale and
Shinde, 2011), Coriander sativum ( Farahani et al., 2008) and alfalfa (Girousse et al.,1996) indicating the importance of AM fungal association on osmotic adjustments. Latef and Chaoxing (2011) have observed low proline content in the leaves of AM treated plants of Tomato when they were subjected to low temperature. They concluded that the change in the leaf proline content is an indication of low degree of injury in mycorrhizal plants so that there is no need to synthesize more proline for osmotic adjustments. However, proline content in leaves has increased when maize plants were inoculated with AM fungi (Chen et al., 2014). Chen et al. (2014) are of the opinion that increased proline content can mitigate the injury caused by low temperature.

It can be concluded from aforesaid data that AM fungal association improves the number of nodules formed along with enhanced mass of the nodules. Further AM fungal association also helps the host to sustain the drought condition by enhancing the synthesis of leghaemoglobin and adjust osmoregulation. Among the two species of Glomus used in the present studies, $G$. mosseae has better compatibility with the host than the $G$. fascicutalum which confirms the host specific character of AM fungi (Smith et al., 2000; Burleigh et al., 2002).

\section{References}

Abd Allah, E.F., Hashem, A., Algarawin, A.A., Bahkali, A.H., Alwhibi, M.S. 2015. Enhancing growth performance and systemic acquired resistance of medicinal plant Sesbaniasesban (L.) Merr. using arbuscular mycorrhizal fungi under salt stress. Saudi J. Biol. Sci., 22: 274-283. 
Abd-Allah, M.H., Wahab, M.A. 1995. Response of $\mathrm{N}_{2}$ fixation, nodule activities and growth to potassium supply in water stressed broad bean. J. Pl. Nutri., 18: 1391-402.

Allen, E.B., Allen, M.F. 1986. Water relations of xeric grasses in the field; interactions of mycorrhizas and competition. New Phytol., 104: 459 571.

Barea, J.M., Azcon-Aguilar, C. 1983. Mycorrhizal and their significance in modulating nitrogen-fixing plants. Adv. Agronomy, 36: 1-54.

Bates, L.S., Waldren, R.P., Teare, L.D. 1973. Rapid determination of free proline for water stress studies. $\mathrm{Pl}$. Soil, 39: 205-207.

Bethlenfalvay, G.J., Brown, M.S., Mihara, K.C., Stafford, A.E. 1987. Effects of Mycorrhizae on nodule activity and transpiration in Soybeans under drought stress. Pl. Physiol., 85: 115119.

Bhartiya, A., Aditya, J.P., Kant, L. 2015. Nutritional and remedial potential of an underutilized food legume Horse gram (Macrotyloma uniflorum): A Review. J. Ani. Pl. Sci., 25: 908 920.

Bhosale, K.S., Shide, B.P. 2011. Influence of arbuscularmycorrhizal fungi on proline and chlorophyll content in Zingiberofficinale Rose grown under water stress. Indian J. Fundamental and Appl. Life Sci., 1: 172-176.

Burleigh, S.H., Cavagnaro, T., Jakobsen, I. 2002. Functional diversity of arbuscularmycorrhizas extends to the expression of plant genes involved in P nutrition. J. Exp. Bot., 53: 15931601.

Chen, X., Song, F., Liu, F., Tian, C., Liu, S., $\mathrm{Xu}$, H., Zhu, X. 2014. Effect of different arbuscularmycorrhizal fungi on growth and physiology of
Maize at ambient and low temperature regimes. The Scientific World online Journal, Article ID956141, 7 pages.

Farahani, A., Lebaschi, H., Hussein, M., Shiranirad, A.H., Valadabadi, A.R., Daneshian, J. 2008. Effect of arbuscularmycorrhizal fungi on different levels of phosphorus and drought stress on water use efficiency, relative water content and proline accumulation rate of coriander (Coriandrum sativum L.). J. Med. Pl. Res., 2: 125-131.

Gianinazzi, S., Gianinazzi - Pearson, V. 1988. Mycorrhizae: A Plants health insurance, Chimica Oggi, Ocobre. 56-58.

Goicoechea, N., Merino, S., Sanchez-Diaz, M. 2005. Arbuscularmycorrhizal fungi can contribute to maintain antioxidant and carbon metabolism in nodules of Anthyllis cytisoides L. subjected to drought. J. Pl. Physiol., 162: 27-35.

Girousse, C., Bournoville, R., Bonnemain, J.L. 1996. Water deficit-induced changes in concentrations in proline and some other amino acids in the Phloem sapof alfalfa. Pl. Physiol., 111: 109-113.

Gonzalez, E.M., Aparicio-Tejo, P.M., Godon, P., Michin, F.R., Royela, M., Arreselgor, C. 1998. Water Deficit Effects on carbon and nitrogen metrbolism of pea nodules, J. Exp. Bot., 49: 1705-1714.

Hazzoumi, Z., Moustakime, Y., Elharchil, E.H., Joutei, K.A. 2015. Effect of arbuscularmycorrhizal fungi (AMF) and water stress on growth, phenolic compounds, glandular hairs, and yield of essential oil in basil (Ocimumgratissimum L.). Chemical and Biological Technologies in Agriculture Springer open Journal. 
Pages 11.

Irigoyen, J., Emerich, D.W., Sancheq-Diaz, M. 1992. Water stress induced changes in concentrations of proline and total soluble sugars in nodulated alfalfa (Medicagosativa) plants. Physiol. Pl., 84: 55-60.

Jia, Y., Gray, V.M., Straker, C.J. 2004. The influence of rhizobium and arbusculrmycorrhizal fungi on nitrogen and phosphorus accumulation by Viciafaba. Ann. Bot., 94: 251-258.

Kohler, J., Hesnandez, J.A., Caravaca, F., Roldan, A. 2008. Plant growth promoting rhizobacteria and arbuscular mycorrhizal fungi modify alleviation biochemical mechanisms in water stressed plants. Funct. Pl. Biol., 35: 141-151.

La Rue, T.A., Child, J.J. 1979. Sensitvefluorometric assay for leg haemoglobin. Anal. Biochem., 92: 11-15.

Latef, A.A.H.A., Chaoxing, H. 2011. Arbuscularmycorrhizal influence on growth, photosynthetic pigments, osmoyic adjustment and oxidative stress in tomato plants subjected to low temperature stress. Acta Physio Pl., 33: 1217-1225.

Loboto, A.K.S., Costa, R.C.L., Neto, O.C.F., Filho, S.B.G., Vidigal, G.M.C., Filho, V.P.S., Silva, C.R., Cruz, F.J.R., Carvalho, P.M.P., Santo, P.C.M., Gonela, A. 2009. Consequences of the water deficit on water relations and symbiosis in Vignaunguiculata cultivars. Pl. Soil Environ., 55: 139-145.

Mishra, R.R., Sharma, G.D., Gathphon, A.R. 1980. Mycorrhizas in ferns of north eastern India. Proceedings of Indian Nat. Sci. Acad., 46: 546-551.

Porcel, R., Barea, J.M., Ruiz-Lozano, J.M. 2003. Antioxidant activities in mycorrhizal soybean plants under drought stress and their possible relationship to the process of nodule senescence. New phytol., 157: 135143.

Reddy, A.M., Kumar, S.G., Jyothsnakumari, G., Thimmanaik, S., Sudhakar, C. 2005. Lead induced changes in antioxdent metabolism of horsegram (Macrotylomauniflorum (Lam.) Verdc.) and bengalgram (Cicerarietinum L.). Chemosphere, 60: 97-104.

Romos, M.L.G., Gordon, A.J., Minchin, F.R., Sprent, J.I., Parsons, R. 1999. Effect of water stress on nodule physiology and biochemistry of a drought tolerant cultivar of common bean (Phaseolus vulgaris L.) Ann. Bot., 83: 57-63.

Ruiz-Lozano, J.M., Azcon, R., Gomez, M. 1995. Effects of Arbuscular mycorrhizalGlomusspecies on drought tolerance: physiological and nutritional plant responses, Appl. Envtl. Microbiol., 61: 456-460.

Ruiz-Lozano, J.M., Collados, C., Barea, J.M., Azcon, R. 2001. Arbuscularmycorrhizal symbiosis can alleviate drought induced nodule senescence in soybean plants. New Phytol., 151: 493-502.

Sarath, G., Pfeiffer, N.E., Sodhi, C.S., Wagner, F.W. 1986. Bacteroids are stable during dark-induced senescence of soybean root nodules. Pl. Physiol., 82: 346-350.

Siddhuraju, P., Manian, S. 2007. The antioxidant activity and free radical scavenging capacityof dietary phenolic extracts from horse gram (Macrotylomauniflotum (Lam.) Vardic.) seeds. Food Chem., 105: 958.

Smith, F.A., Jacobsen, I., Smith, S.E. 2000. Spatial differences in acquisition of 
soil phosphate between two arbuscularmycorrhizal fungi in symbiosis with Medicagotrunculata. New Phytol., 147: 357-366.

Snedecor, G.W., Cochron, W.G. 1994. Statistical Methods. 8th Edn IOWA State University Press, Ames, IOWA, USA.

Sudha, N., Begum, J.M., Shambulingappa, K.G., Babu, C.K. 1995. Nutrients and some anti-nutrients in horsegram( Macrotylomauniflorum (Lam.) Verdc.). Food and Nutri. Bull., 16.

Tajini, F., Trabelsi, M., Drevon, J. 2012. Combined inoculation with Glomusintraradices and Rhizobium tropiciCIAT 899 increases phosphorus use efficiency for symbiotic nitrogen fixation in common pea (Phaseolus vulgaris)
Saudi J. Biol. Sci., 19: 157-163.

Trotel-Aziz, P., Niogret, M.F., Larher, F. 2000. Proline level is partly under the control of abscisic acid in canola leaf discs during recovery from hyper osmotic stress. Physiol. Pl., 110: 376-383.

Varma, A., Hock, B. 1998. Mycorrhiza: structure, function, molecular biology and biotechnology, Springerverlag, Berlin, Germany.

Williams, P.G., Rose, D.J., Seppett, R.D. 1994. Mycorrhizas of hepatics in continental Antarctica. Mycol. Res., 98: 34-36.

Younis, M. 2002. Nodulation and nitrogen fixation by Lupinusvarins L. a wild type of lupine grown in the southern part of the eastern desert of Egypt under different water regimes. J. Biol. Sci., 2: 596-600.

\section{How to cite this article:}

Savitha M. Murthy, P. Anitha, B.S. Sumalatha and Tejavathi, D.H. 2016. Effect of Mycorrhizal Association on Nodule Number, Mass, Leghaemoglobin and Free Proline Content in Macrotyloma uniflorum (Lam.) Verdc. Under PEG Induced Water Stress. Int.J.Curr.Microbiol.App.Sci. 5(4): 165-174. doi: http://dx.doi.org/10.20546/ijcmas.2016.504.021 